\title{
Exertional Rhabdomyolysis (ER) in Arabian Horses
}

\section{Wael M. EL-Deeb*}

\section{Department of Clinical Studies, College of Veterinary Medicine and Animal Resources, King Faisal University, Saudi Arabia}

This editorial to the Journal of Veterinary Science and Technology is focused on ER in Arabian horses. Muscle disorders are a common cause of suboptimal performance or even disability to perform. In comparison to human medicine, the etiology of muscle disorders in equine medicine is less explored. Tying-up or ER was previously known as Monday-morning disease. Monday morning disease was associated with work horses that was given a day of rest after a week of hard work. When the horses were supposed to return to work on the following Monday, they developed stiffness and pain in the hindquarter musculature, and reluctance to move. Arabians horses are one of the affected breeds. The underlying cause of this metabolic disorder is not yet known but is thought to involve carbohydrate metabolism. Clinical signs of ER, including muscle pain, cramping, stiffness, sweating, exercise intolerance, weakness, and reluctance to move may be observed, with the hindquarters most frequently affected. In order to confirm a diagnosis of ER, blood samples should be obtained to determine creatin kinase (CK) and aspartate transaminase (AST). Their elevation indicates muscle damage and confirms the diagnosis of the disease. In addition, AST activity may be heightened in asymptomatic horses with chronic ER. Exercise has been shown to induce tissue damage by oxidation of cellular components, such as membrane lipids, proteins, carbohydrates and DNA. The main sources of reactive oxygen species (ROS) that are generated during exercise are the mitochondria (respiratory chain), although activated phagocytes (respiratory burst) and several enzymes such as oxidases perhaps contribute to an increased ROS release. Living organisms possess antioxidant defense systems against ROS. These defense systems include endogen antioxidants, which can be classified as non enzymatic (vitamin E, vitamin C, uric acid) and enzymatic defense system. The most important antioxidant enzymes are super oxide dismutase (SOD) and (catalase) CAT. If the pro-oxidant burden overwhelms the endogenous antioxidant defenses of the organism, the arising imbalance between pro- and antioxidants is resulted which defined as oxidative stress. Exercise-induced oxidative stress is believed to contribute to accelerated muscle fatigue and muscle fiber damage, leading to exercise intolerance and poor performance in different animal species, as well as to a decreased immune defense of the organism. If the importance of antioxidant deficiencies for exercise-induced oxidative stress and exercise intolerance has been clearly established, thereby that supplementation of antioxidants might improve performance, remains to be proven. Electrolyte imbalances were believed to have an important role in causing ER in race horses. Studies by Harris and Snow (1991) in the United Kingdom have focused on determining electrolyte balance in horses with tying-up. Commercial diets were found to be too low in salt (sodium chloride) and most horses needed an additional 1-2 ounces of salt to maintain proper balance. While some horses improved dramatically by adding electrolytes in the form of table salt (sodium chloride), lite salt (potassium chloride), or Epsom salt (magnesium chloride), other horses showed no improvement. Trace-elements, such as selenium (Se), zinc $(\mathrm{Zn})$, copper $(\mathrm{Cu})$ and manganese $(\mathrm{Mn})$ play an important catalytic role for the enzymatic activity of SOD. Strenuous exercise induced a transient endotoxemia and a pro-inflammatory condition in the horse that persists for approximately $2 \mathrm{~h}$ after exercise. IL- 6 is an important mediator of inflammation. The pleiotrophic cytokine IL-6 is involved in directing the innate immune response to acquired immunity, and has been described as a regulatory cytokine in osteoarthritis. It stimulates production of metalloproteinase inhibitors, but also potentiates the catabolic effects of IL-1 and TNF- $\alpha$ on proteoglycan metabolism. Recently in Arabian horses it was reported by EL-Deeb and Al-Bahr (2010) that pro-inflammatory cytokines (TNF- $\alpha$, IL6) and PGF2- $\alpha$ concentrations could be added to other traditional biomarkers (CK, AST and LDH) used for the diagnosis of ER in Arabian horses. In the future, efforts should be made to confirm this in other breed. If this could be achieved, it would yield a valuable tool to diagnose ER and would open up new perspectives in research fields dealing with ER not only in animals, but also in humans.
*Corresponding author: Dr. Wael M. EL-Deeb, Associate Professor, Department of Clinical Studies, College of Veterinary Medicine and Animal Resources, King Faisal University, Saudi Arabia, Tel: (00966) (050) 9296154; Fax: (00966) (03) 5816635; E-mail: drwaeleldeeb@yahoo.com

Received April 04, 2012; Accepted April 04, 2012; Published April 10, 2012

Citation: EL-Deeb WM (2012) Exertional Rhabdomyolysis (ER) in Arabian Horses. J Veterinar Sci Technol 3:e101. doi:10.4172/2157-7579.1000e101

Copyright: ( 2012 EL-Deeb WM. This is an open-access article distributed under the terms of the Creative Commons Attribution License, which permits unrestricted use, distribution, and reproduction in any medium, provided the original author and source are credited. 